\title{
ANALISA DAN AUDIT TATA KELOLA TEKNOLOGI INFORMASI DENGAN COBIT 5 FRAMEWORK P.O.07 PADA BIRO ADMINISTRASI UMUM UNIVERSITAS MUHAMMADIYAH PALANGKARAYA
}

\author{
Analysis and Audit of Information Technology Governance Using Cobit 5 Framework P.0.07 at \\ the General Administration Bureau of the University of Muhammadiyah Palangkaraya
}

\author{
Ika Safitri Windiarti' \\ Fitriani $^{2}$ \\ Mita Sari ${ }^{3}$ \\ Agung Prabowo ${ }^{4}$ \\ 'Dosen Program Studi IImu \\ Komputer, Fakultas Teknik. \\ Universitas Muhammadiyah \\ Palangkaraya. \\ ${ }^{2,3}$ Dosen Program Studi \\ Administrasi Negara, Fisip. \\ Universitas Muhammadiyah \\ Palangkaraya. \\ ${ }^{4}$ Dosen Program Studi \\ Sitem Informasi \\ STMIK Palangkaraya \\ *email: \\ ikasafitri@gmail.com
}

\begin{abstract}
Abstrak
Tata kelola teknologi informasi adalah bagian yang terintegrasi dari pengelolaan organisasi yang mencakup kepemimpinan, struktur serta proses organisasi yang memastikan bahwa teknologi informasi dimanfaatkan seoptimal mungkin. Suatu institusi setaraf UMP terutama di bagian BAU, sudah saatnya dikelola dengan berbasis $\mathrm{TI}$ mengingat kompleksitas pekerjaan dan untuk efisiensi dan efektivitas kerja karyawan yang berkerja di BAU UMP. Tujuan penelitian ini adalah untuk mengetahui kondisi tata kelola TI di BAU UMP untuk saat ini dan menganalisa kebutuhan TI untuk 5-10 tahun yang akan datang dengan menerapkan metode COBIT 5 Framework. Berdasarkan data responden, untuk 5-10 tahun yang akan datang, BAU UM Palangkaraya memerlukan paling tidak 6 orang staff dengan latar pendidikan IT atau IImu Komputer untuk masing-masing bagian sebanyak I orang staff. Untuk penelitian kelanjutannya adalah bekerja pada subdomain PO.08 dan PO 09.
\end{abstract}

\begin{abstract}
Information technology governance is an integrated part of organizational management that includes leadership, organizational structure and processes that ensure that information technology is utilized as optimal as possible. An institution similar to UMP, especially in the BAU section, it is time to be managed on an IT-based basis in view of the complexity of the work and for the efficiency and effectiveness of the work of employees working at BAU UMP. The purpose of this study is to determine the condition of IT governance in the UMP BAU for now and analyze IT needs for the next 5-10 years by applying the COBIT 5 Framework method. Based on respondent data, for the next 5-10 years, BAU UM Palangkaraya requires at least 6 staff with educational background in IT or Computer Science for each section of I staff member. For further research is to work on subdomains PO.08 and PO 09.
\end{abstract}




\section{PENDAHULUAN}

$\mathrm{Di}$ era globalisasi ini perkembangan teknologi informasi menunjukkan bahwa masyarakat dunia sudah sangat membutuhkan adanya teknologi yang cepat dan akurat. Perkembangan sistem teknologi informasi menyebabkan perubahan- perubahan peran mulai dari peran efisiensi, efektivitas sampai pada peran strategik. Teknologi informasi (TI) tidak hanya difungsikan sebagai pendukung (support) tapi menjadi bagian atau penentu kesuksesan. Hal ini dibuktikan dengan adanya fakta bahwa pengelolaan TI diarahkan untuk peningkatan kinerja suatu organisasi dan merupakan tanggung jawab seluruh manajemen dalam organsisasi. Tata kelola teknologi informasi adalah bagian yang terintegrasi dari pengelolaan organisasi yang mencakup kepemimpinan, struktur serta proses organisasi yang memastikan bahwa teknologi informasi dimanfaatkan seoptimal mungkin. Pada penelitian ini dilakukan analisa dan audit tata kelola teknologi pada Biro Administrasi Umum (BAU) Universitas Muhammadiyah Palangkaraya (UMP) dengan menggunakan COBIT 5 Framework pada Domain P.O. 7 yang meliputi IT Human Resources atau Sumber Daya Manusia Teknologi Informasi (SDM-TI).

Hal yang melandasi peneliti ingin melakukan penelitian ini adalah bahwa dalam suatu institusi setaraf UMP terutama di bagian BAU, sudah saatnya dikelola dengan berbasis TI mengingat kompleksitas pekerjaan dan untuk efisiensi dan efektivitas kerja karyawan yang berkerja di BAU UMP. UMP dengan mahasiswa aktif sejumlah kurang lebih 4500 mahasiswa dan arus kegiatan belajar mengajar yang sangat aktif dan padat, akan sulit untuk dikelola apabila tidak menggunakan adanya implementasi TI.

Rumusan masalah dalam penelitian ini didasarkan pada kondisi saat ini di BAU UMP, tata kelola TI masih bersifat stand-alone artinya bahwa pemanfaatan TI dalam mendukung pekerjaan di BAU UMP sudah ada tetapi masih berdiri sendiri-sendiri di masingmasing bagian. Belum ada suatu sistem yang terintegrasi untuk mengelola $\mathrm{TI}$ tersebut. Kondisi awal ini perlu adanya assessment (penilaian) dengan menggunakan COBIT 5 Framework untuk mengetahui baseline analisa dan auditnya.

Adapun tujuan diadakannya penelitian ini adalah untuk mengetahui kondisi tata kelola TI di BAU UMP untuk saat ini dan menganalisa kebutuhan TI untuk 510 tahun yang akan datang dengan menerapkan metode COBIT 5 Framework. Hasil dari penelitian ini nantinya akan digunakan sebagai baseline analisa kebutuhan tenaga SDM TI di BAU UMP serta sebagai acuan rekomendasi penerapan aplikasi digitalisasi data dan informasi di Universitas Muhammadiyah
Palangkaraya.

\section{TINJAUAN PUSTAKA}

Terdapat 5 lingkup proses tata kelola berdasarkan peraturan Menteri Komunikasi dan Informatika Nomor: 4I/PER/MEN/KOMINFO/I I/2007, yaitu:

I. Perencanaan sistem yaitu proses ini menangani identifikasi kebutuhan organisasi dan formulasi inisiatif-inisiatif $\mathrm{TI}$ yang dapat memenuhi kebutuhan organisasi tersebut.

2. Manajemen belanja/investasi yaitu proses yang menangani pengelolaan investasi/belanja $\mathrm{Tl}$.

3. Realisasi sistem yaitu proses ini menangani pemilihan, penetapan, pengembangan sistem TI, serta manajemen proyek TI.

4. Pengoperasian sistem yaitu proses ini menangani operasi TI yang memberikan jaminan tingkat layanan dan keamanan sistem TI yang dioperasikan.

5. Pemeliharaan sistem yaitu proses ini menangani pemeliharaan asset- aset $\mathrm{TI}$ untuk mendukung pengoperasian sistem yang optimal.

Penerapan teknologi informasi memiliki nilai investasi yang tinggi sehingga perlu adanya pengelolaan TI yang signifikan. Melalui pengelolaan TI yang baik maka proses TI yang ada dapat berjalan secara sistematis, terkendali, efektif, efisien, dapat mengurangi biaya operasional dan meningkatkan daya saing. Hasil yang baik dari sebuah pengelolaan $\mathrm{TI}$ dapat dicapai jika dikembangkan dengan menggunakan IT Framework berstandar Internasional salah satunya adalah Control Objective for Information and Related Technology (COBIT).

COBIT (Control Objective for Information and related Technology) merupakan sekumpulan dokumentasi dan panduan untuk mengimplementasikan IT Governance, kerangka kerja yang membantu auditor, manajemen dan pengguna (user) untuk menjembatani pemisah (gap) antara resiko bisnis, kebutuhan kontrol dan permasalahan- permasalahan teknis. COBIT dikembangkan oleh IT Governance Institute (ITGI) yang merupakan bagian dari Information System Audit and Control Association (ISACA. 20I2).

Terdapat kelebihan dan kekurangan pada kerangka kerja COBIT. Kelebihan dari COBIT yaitu efektif dan efisien, berhubungan dengan informasi yang relevan terkait dengan proses bisnis, integritas, ketepatan dan kelengkapan informasi yang diberikan dan proteksi terhadap informasi sensitif dari pihak yang tidak bertanggung jawab. Sedangkan kekurangan dari COBIT yaitu COBIT hanya berfokus pada kendali dan pengukuran, tidak memberikan panduan implementasi operasional maka perlu mengadopsi 
berbagai kerangka kerja lain seperti Infrastructure Library dan kerumitan dalam penerapan.

COBIT 5 adalah sebuah kerangka kerja untuk tata kelola dan manajemen teknologi informasi dan semua yang berhubungan, yang dimulai dari memenuhi kebutuhan stakeholder akan informasi dan teknologi (ISACA, 20I2). COBIT 5 memiliki 2 (dua) area utama yaitu area tata kelola (governance) dan area manajemen (management). Pengaturan (Govern) terkait hal-hal apa yang mendasari tata kelola tersebut yang ditentukan melalui pendefinisian strategi dan kontrol. Sedangkan pengelolaan (manage) terkait bagaimana tata kelola tersebut dilaksanakan merupakan cakupan dari pengelolaan (manage) yang ditentukan melalui rencana taktis.

Prinsip ini menjelaskan bahwa dalam kerangka kerja (framework) COBIT 5 membuat perbedaan yang jelas diantara tata kelola (governance) dan manajemen (management). Tata kelola (governance) melibatkan pengambilan keputusan pada high level, tanggung jawab direksi di bawah kepemimpinan ketua. Sedangkan, manajemen (management) adalah tanggung jawab manajemen eksekutif dibawah kepemimpinan CEO.

Tabel I Perbedaan Mengatur dan Menatakelola TI (Jogiyanto dan Abdillah, 20I I)

\begin{tabular}{|ccc|}
\hline Kriteria & $\begin{array}{c}\text { Mengatur (Manage) TI } \\
\text { Latasan (Scope) }\end{array}$ & $\begin{array}{c}\text { Menata kelola (govern) TI } \\
\text { Lebih sempit karena bagian } \\
\text { dari tata kelola TI }\end{array}$ \\
\hline Mekanisme & Departemen TI & Korporasi \\
\hline Keputusan TI & Keputusan TI spesifik & Keputusan TI korporat \\
\hline Fokus & Proses internal & Internal dan eksternal \\
\hline Horison & Sekarang jan jangka & Jangka panjang \\
\hline Objek keputusan & Keputusan yang dibuat & $\begin{array}{c}\text { Siapa dan bagaimana } \\
\text { membuat keputusan }\end{array}$ \\
\hline Proses implementasi & Dapat dialihkan \\
(outsourcing) & Tidak dapat dialihkan \\
\hline Pihak yang bertanggung & Manajer TI (ClO) & Dewan direksi termasuk \\
Jawab & ClO \\
\hline \hline
\end{tabular}

Dalam penerapan COBIT 5 Framework ada sekumpulan I55tatis yang mempengaruhi sesuatu yang akan dikerjakan oleh organisasi yang disebut sebagai Enablers (ISACA, 20I2). Dalam hal ini terkait pengelolaan teknologi informasi di organisasi, yaitu:

I. Prinsip, Kebijakan dan Kerangka Kerja (Principles, Policies and Framework); adalah alat atau pendorong untuk menerjemahkan tingkah laku ke dalam panduan praktis untuk manajemen sehari-hari.

2. Proses (Processes); menjelaskan tentang sekumpulan kegiatan yang terorganisir untuk mencapai tujuan tertentu dan menghasilkan sekumpulan output dalam mendukung pencapaian tujuan IT.

3. Struktur Organisasi (Organizational Structures); adalah entitas dalam organisasi sebagai kunci dalam membuat keputusan.

4. Budaya, Etika dan Perilaku (Culture, Ethics and
Behaviour); merupakan 155tatis keberhasilan dalam kegiatan tata kelola dan manajemen.

5. Informasi (Information); dalam organisasi terdiri dari informasi yang dihasilkan dan digunakan. Informasi dibutuhkan agar organisasi dapat berjalan dengan baik.

6. Layanan, Infrastruktur dan Aplikasi (Service, Infrastructure and Applications); melibatkan infrastruktur teknologi dan aplikasi yang menyediakan proses dan layanan teknologi informasi bagi organisasi/organisasi.

7. Orang, Kemampuan dan Kompetensi (People, skills and competencies); berhubungan dengan seorang individu dan kebutuhan untuk memenuhi semua aktifitas untuk mencapai kesuksesan dan membuat keputusan yang tepat dengan langkah yang tepat.

Idealnya dalam analisa dan audit tata kelola TI di suatu organisasi, melibatkan secara keseluruhan 5 
framework yang ada sebagai standar, Akan tetapi dalam implementasinya, suatu organisasi menganalisa dan mengaudit tata kelola $\mathrm{TI}$ menggunakan framework dan domain yang relevan saja, yang pada saat itu diperlukan untuk dianalisa dan diaudit.

Ada 5 Framework Utama dalam COBIT 5, seperti pada Gambar 2.I berikut

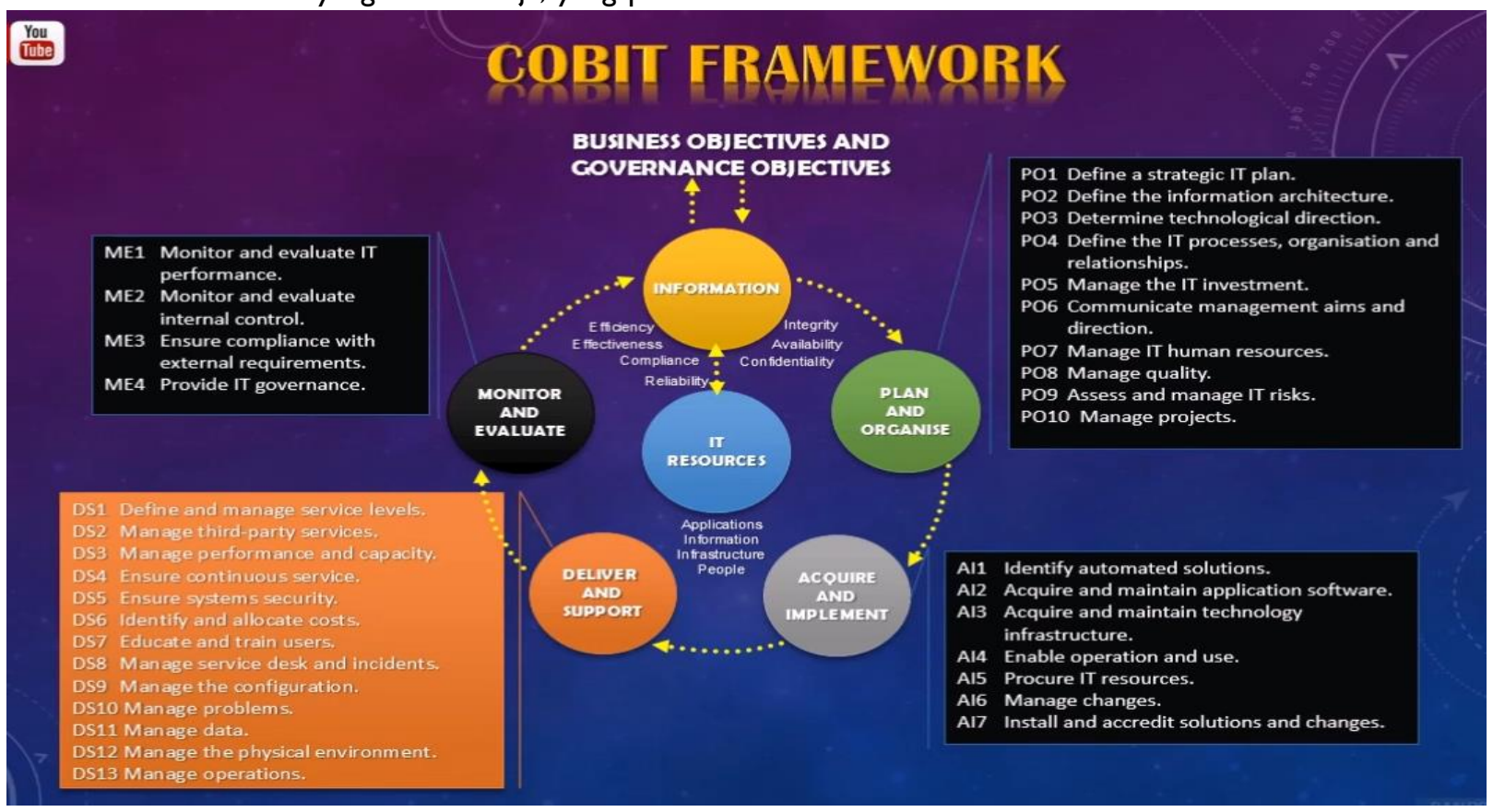

Gambar .I. Cobit Framework

Adapun penjelasan domain tiap-tiap framework dijelaskan pada table 2 yang meliputi total sejumlah 34 Domain Proses COBIT, Skor dan tingkat Maturity dari tiap proses.

Tabel 2 Domain, skor dan tingkat maturity

\begin{tabular}{lllll}
\hline \multicolumn{7}{l}{ Plan and Organize } & & \\
\hline NO & KODE & PROSES & SKOR & TINGKAT \\
& & & MATURITY \\
I & POI & Menetapkan rencana Strategis TI & 3 & Define \\
$\mathbf{2}$ & PO2 & Menetapkan arsitektur I56tatis informasi & 0 & Non-Existent \\
$\mathbf{3}$ & PO3 & Menetapkan arah teknologi & 3 & Define \\
$\mathbf{4}$ & PO4 & Menetapkan proses TI, organisasi dan hubungannya & 3 & Define \\
$\mathbf{5}$ & PO5 & Mengatur investasi TI & 3 & Define \\
$\mathbf{6}$ & PO6 & Mengkomunikasikan tujuan dan arahan manajemen & 4 & Manage \\
$\mathbf{7}$ & PO7 & Mengelola sumberdaya manusia & 4 & Manage \\
$\mathbf{8}$ & PO8 & Mengatur kualitas & 3 & Define \\
$\mathbf{9}$ & PO9 & Menilai dan mengatur resiko TI & 0 & Non-Existent \\
I 0 & POI0 & Mengatur Proyek & 0 & Non-Existent \\
\hline Acquire and Implement & 2.3 & Repeatable \\
\hline
\end{tabular}


Ika Safitri Windiarti,Fitriani,Mita Sari.2019.Analisa Dan Audit Tata Kelola Teknologi Informasi Dengan Cobit 5 Framework P.O.07 Pada Biro Administrasi Umum Universitas Muhammadiyah Palangkaraya.

\begin{tabular}{|c|c|c|c|c|}
\hline NO & KODE & PROSES & SKOR & $\begin{array}{l}\text { TINGKAT } \\
\text { MATURITY }\end{array}$ \\
\hline I & All & Identifikasi solusi-solusi otomatis & 0 & Non-Existent \\
\hline 2 & $\mathrm{Al} 2$ & Mendapatkan dan memelihara perangkat lunak aplikasi & 3 & Define \\
\hline 3 & $\mathrm{Al} 3$ & Mendapatkan dan memelihara infrastruktur teknologi & 3 & Define \\
\hline 4 & $\mathrm{Al} 4$ & Menjalankan operasi dan menggunakannya & 3 & Define \\
\hline 5 & $\mathrm{Al} 5$ & Pengadaan sumber daya TI & 3 & Define \\
\hline 6 & $\mathrm{Al} 6$ & Mengelola perubahan & 0 & Non-Existent \\
\hline \multirow[t]{2}{*}{7} & Al7 & Instalasi dan akreditasi solusi serta perubahan & 0 & Non-Existent \\
\hline & & Rata-rata Domain Al & 1.7 & Repeatable \\
\hline \multicolumn{5}{|c|}{ Delivery and Support } \\
\hline NO & KODE & PROSES & SKOR & $\begin{array}{l}\text { TINGKAT } \\
\text { MATURITY }\end{array}$ \\
\hline I & DSI & Menetapkan dan mengatur tingkat layanan & 0 & Non-Existent \\
\hline 2 & DS2 & Pengaturan layanan dengan pihak ketiga & 3 & Define \\
\hline 3 & DS3 & Mengatur kinerja dan kapasitas & 0 & Non-Existent \\
\hline 4 & DS4 & Memastikan ketersediaan layanan & 3 & Define \\
\hline 5 & DS5 & Memastikan keamanan sistem & 3 & Define \\
\hline 6 & DS6 & Identifikasi dan biaya tambahan & 0 & Non-Existent \\
\hline 7 & DS7 & Mendidik dan melatih user & 3 & Define \\
\hline 8 & DS8 & Mengelola bantuan layanan dan insiden & 0 & Non-Existent \\
\hline 9 & DS9 & Mengatur konfigurasi & 0 & Non-Existent \\
\hline 10 & DSIO & Mengelola masalah & 0 & Non-Existent \\
\hline I I & DSII & Mengelola data & 3 & Define \\
\hline 12 & DSI 2 & Mengelola fasilitas & 3 & Define \\
\hline \multirow[t]{2}{*}{13} & DSI3 & Mengelola operasi & 3 & Define \\
\hline & & Rata-rata Domain DS & 1.6 & Repeatable \\
\hline \multicolumn{5}{|c|}{ Monitor and Evaluate } \\
\hline NO & KODE & PROSES & SKOR & $\begin{array}{l}\text { TINGKAT } \\
\text { MATURITY }\end{array}$ \\
\hline I & MEI & Monitor dan Evaluasi Kinerja TI & 3 & Define \\
\hline 2 & ME2 & Monitor dan Evaluasi Pengendalian Internal & 3 & Define \\
\hline 3 & ME3 & Mendapatkan jaminan independent & 0 & Non-Existent \\
\hline \multirow[t]{2}{*}{4} & ME4 & Penyediaan untuk tatakelola TI & 3 & Define \\
\hline & & Rata-rata Domain ME & 2.3 & Repeatable \\
\hline
\end{tabular}

Pada penelitian ini, digunakan domain PO 07 yaitu Mengelola Sumberdaya Manusia dengan skor 4 dan tingkat maturity Manage. Pada proses ini menjelaskan tentang melakukan pendekatan terstruktur untuk memastikan struktur yang optimal, penempatan, hak keputusan dan keterampilan sumber daya manusia.

\section{METODE PENELITIAN}

Penelitian ini menggunakan metode kualitatif karena objek penelitiannya bersifat alamiah. Metode penelitian kualitatif digunakan untuk meneliti suatu objek yang alamiah yang menghasilkan data deskriptif berupa kata-kata tertulis atau lisan dari objek penelitian yang diamati (Sugiyono, 2013).

\section{A. Metode Pengumpulan Data}


Pada penelitian ini dilakukan pengumpulan data. Data yang digunakan yaitu:

I) Data primer adalah data yang diperoleh langsung di lapangan, yaitu:

- Observasi; adalah teknik atau pendekatan untuk memperoleh data dengan cara mengamati langsung objek datanya 1 .

- Wawancara; adalah komunikasi dua arah untuk mendapatkan data dari responden. Wawancara dilakukan untuk menemukan masalah secara lebih terbuka melalui pendapat dan ide yang disampaikan oleh responden (Sugiyono, 2012).

- Kuesioner; adalah teknik pengumpulan data yang dilakukan dengan cara memberi seperangkat pertanyaan atau pernyataan tertulis kepada responden untuk dijawabnya (Sugiyono, 20I2).

2) Data sekunder adalah data yang diperoleh $\begin{array}{llrr}\text { dari beberapa kajian } & \text { pustaka yang } \\ \text { berhubungan dengan } & \text { I58tati dan }\end{array}$ permasalahan pada penelitian, yaitu:

- $\quad$ Studi Literatur; adalah proses kegiatan menelaah dan membaca bahan pustaka seperti buku-buku, dokumen, mempelajari penelitian sejenis yang pernah dilakukan orang lain, serta mempelajari mengenai I58tati terkait penelitian yang dilakukan (Sanjaya, 2013).

\section{B. Metode Analisis Data}

Penelitian ini menggunakan teknik analisis data deskriptif kualitatif yang menekankan pada sumber data dan fakta. Kemudian data dikembangkan dengan acuan pada capability level COBIT 5 dan skala pengukuran Likert.

ANALISA DATA DAN PEMBAHASAN

Dari hasil analisa profil responden yang dilibatkan dalam penelitian ini, maka diperoleh secara statistik jumlah personil dengan latar belakang pendidikan non IT yaitu sebesar I5 orang.

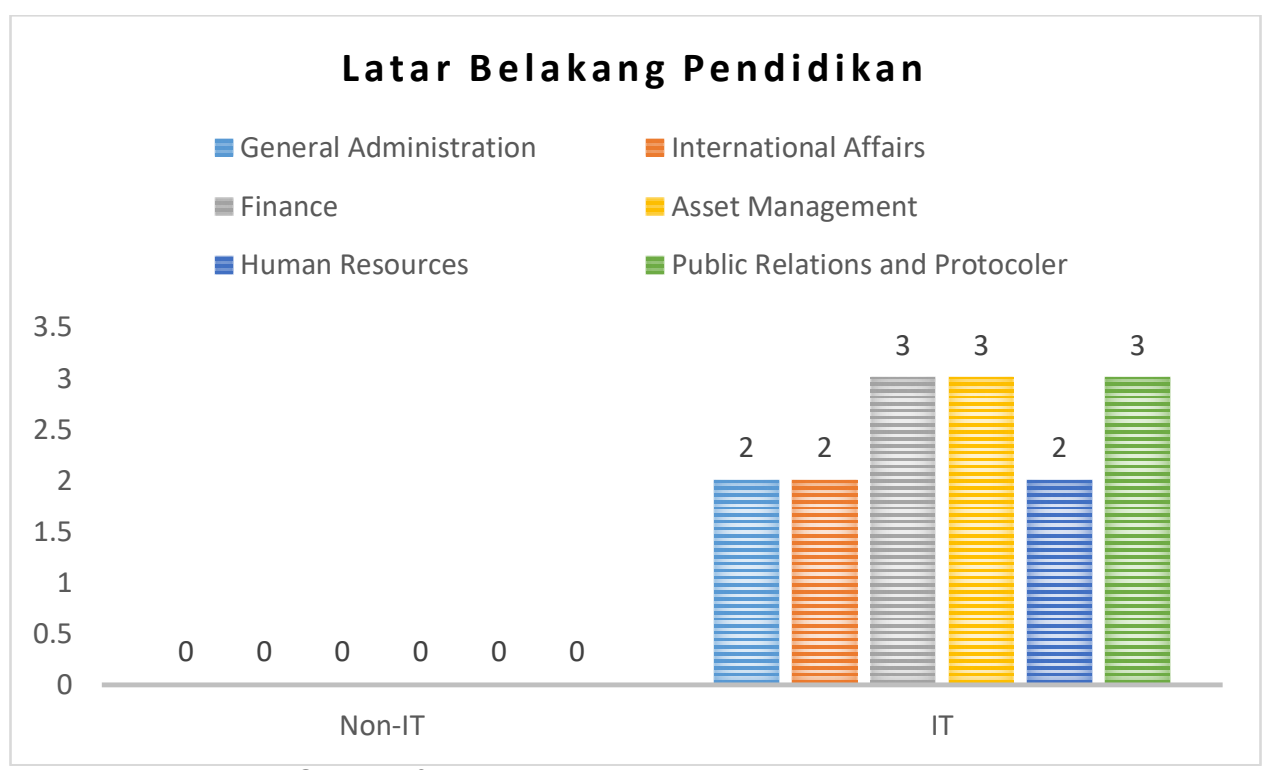

Gambar 2. Latar Belakang Pendidikan Responden

Menurut hasil observasi di lapangan, ada 2 orang di bagian Humas dan Protokoler yang memiliki kemampuan IT secara otodidak, yaitu dibidang desain grafis dan video making/editing. Selebihnya, mereka memiliki kemampuan IT sebagai lever operator yaitu menguasai Microsoft Word, Excell dan Powerpoint. Selain itu mereka mampu bertindak sebagai Internet
Super User di tingkat Basic, yaitu menggunakan web browser, email, aplikasi-aplikasi sederhana, serta mengoperasikan printer dan scanner.

Setelah dilakukan wawancara dan Tanya jawab kuisioner, maka diperoleh pendapat para resonden dengan keterangan seperti pada Gambar 3 berikut ini: 


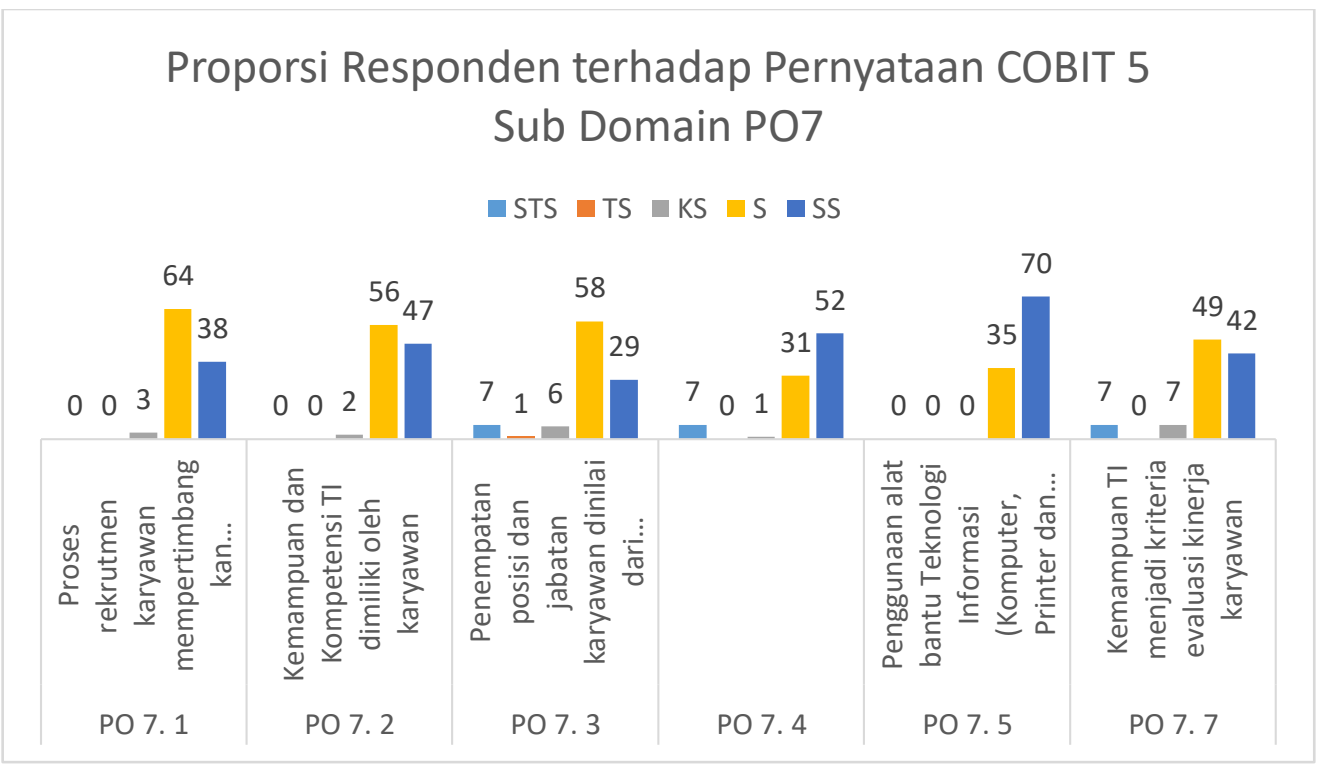

Dari hasil pendapat mereka pada kuesioner tersebut, maka dapat dianalisa bawa staff di BAU UM Palangkaraya sudah sangat menyadari adanya kebutuhan akan kemampuan/skill di bidang IT untuk bidang pekerjaan mereka. Secara detil mereka merincikannya di dalam proses wawancara.

Harapannya adalah bias dilakukan penambahan staff IT di tiap bagian di BAU UM Palangkaraya.

\section{KESIMPULAN DAN SARAN}

\section{A. KESIMPULAN}

I. Berdasarkan data responden, untuk 5-10 tahun yang akan datang, BAU UM Palangkaraya memerlukan paling tidak 6 orang staff dengan latar pendidikan IT atau IImu Komputer untuk masing-masing bagian sebanyak I orang staff

2. Ada beberapa staff yang walaupun tidak memiliki latar belakang IT, tetapi punya ketrampilan IT yang didapatkan secara otodidak, dan hal ini perlu untuk diapresiasi, dan kepada mereka perlu diberikan training secara berkala.

DAFTAR PUSTAKA

ISACA. 20I2. COBIT 5 A Business Framework for the Governance and Management of Enterprise IT. USA: IT Governance Institute.

ISACA. 2012. COBIT 5 Enabling Processes. USA: IT Governance Institute.

ISACA. 20I 3. COBIT 5 Process Assessment Model. USA: IT Governance Institute

Jogiyanto, H.M. \& Abdillah, W. 20II. Sistem Tata Kelola Teknologi Informasi.

Yogyakarta: ANDI

Sugiyono. 2012. Memahami Penelitian Kualitatif. Bandung: ALFABETA.

Sugiyono. 2010. Metode Penelitian Kuantitatif Kualitatif \& RND. Bandung: Alfabeta

\section{B. SARAN}

1. BAU UM Palangkaraya sangat memerlukan SDM berlatar belakang IT

2. Rekomendasi ini sesuai dan bisa diimplementasikan di BAU UM Palangkaraya

3. Untuk kelanjutan riset ini bias dikembangkan sub domain PO 8 (Manage Quality) dan PO9 (Manage IT Risks) 